Hydrology and Earth System Sciences, 7(6), 877-889 (2003) C EGU

\title{
Hydrometeorological aspects of the Real-Time Ultrafinescale Forecast Support during the Special Observing Period of the MAP* $^{*}$
}

\author{
R. Benoit ${ }^{1}$, N. Kouwen ${ }^{2}$, W. Yu ${ }^{1}$, S. Chamberland ${ }^{1}$ and P. Pellerin ${ }^{1}$ \\ ${ }^{1}$ Recherche en Prévision Numérique (RPN), 2121 TransCanada Highway, Dorval, QC, Canada H9P 1J3 \\ ${ }^{2}$ Department of Civil Engineering, University of Waterloo, Waterloo, ON, Canada N2L 3G1 \\ Email for corresponding author: Wei.Yu@ec.gc.ca
}

\begin{abstract}
During the Special Observation Period (SOP, 7 September-15 November, 1999) of the Mesoscale Alpine Programme (MAP), the Canadian Mesoscale Compressible Community Model (MC2) was run in real time at a horizontal resolution of $3 \mathrm{~km}$ on a computational domain of $350 \times 300 \times 50$ grid points, covering the whole of the Alpine region. The WATFLOOD model was passively coupled to the MC2; the former is an integrated set of computer programs to forecast flood flows, using all available data, for catchments with response times ranging from one hour to several weeks. The unique aspect of this contribution is the operational application of numerical weather prediction data to forecast flows over a very large, multinational domain. An overview of the system performance from the hydrometeorological aspect is presented, mostly for the real-time results, but also from subsequent analyses. A streamflow validation of the precipitation is included for large basins covering upper parts of the Rhine and the Rhone, and parts of the Po and of the Danube. In general, the MC2/WATFLOOD model underestimated the total runoff because of the under-prediction of precipitation by MC2 during the MAP SOP. After the field experiment, a coding error in the cloud microphysics scheme of MC2 explains this underestimation to a large extent. A sensitivity study revealed that the simulated flows reproduce the major features of the observed flow record for most of the flow stations. The experiment was considered successful because two out of three possible flood events in the Swiss-Italian border region were predicted correctly by data from the numerical weather models linked to the hydrological model and no flow events were missed. This study has demonstrated that a flow forecast from a coupled atmospherichydrological model can serve as a useful first alert and quantitative forecast.
\end{abstract}

Keywords: mesoscale atmospheric model, hydrological model, flood forecasting, Alps

\section{Introduction}

During the Special Observation Period (SOP, Sep. 7 - Nov. 15, 1999) of the MAP (Bougeault et al., 2001), the Canadian Mesoscale Compressible Community Model (MC2) was run in a real-time NWP (Numerical Weather Prediction) mode at a horizontal resolution of $3 \mathrm{~km}$ on a computational domain of $350 \times 300 \times 50$ grid points, covering the whole of the Alpine region. These high resolution numerical weather prediction data helped to issue early weather warnings, to plan for aircraft missions during the SOP, and to provide final

\footnotetext{
* Portions of this paper were presented at the International Conference on Flood Estimation March 6-8, 2002, Berne, Switzerland
}

mission decision and fine-tuning of the operation. At the same time, the MC2-predicted precipitation and temperature data were also used to drive a hydrological model, WATFLOOD, to conduct a real-time flood forecasting experiment. The overall performance of the MC2 in supporting the MAP SOP has been reported by Benoit et al. (2002). The present contribution is focused on the hydrometeorological aspects of the MC2's real-time forecast support.

\section{The models and coupling strategies}

MC2 is a compressible non-hydrostatic Limited Area Model (LAM). It is based on the Euler equations with a semi- 
implicit, semi-Lagrangian discretisation (Tanguay et al., 1990; Benoit et al., 1997). The version 4.7 of MC2 was used to produce high-resolution $(3 \mathrm{~km})$ forecasts during the entire MAP SOP period. Detailed descriptions of the model dynamics and physics used in the experiment can be found in Benoit et al. (2002). However, some physical parameterisations such as cloud/precipitation and land surface schemes, must be discussed since near-surface precipitation and temperature are key inputs to the hydrological model for flow forecasting. Note that the topography is filtered to about $5 \mathrm{Dx}$, about equivalent to the SM terrain: this affects the orographic precipitation.

The cloud and precipitation processes are simulated with an explicit cloud microphysics scheme (Kong and Yau, 1997) which includes both ice crystals and graupels (Misra et al., 2000). The code of the scheme was fully vectorised so as to keep up with the fast processing of the dynamics. The four cloud species (cloud water, rain water, ice crystals, and graupels) are advected with the 3D semi-Lagrangian method of the dynamics. This scheme performs well in simulating the fine features of a mesoscale convective system at a resolution of $2 \mathrm{~km}$ (Bélair and Mailhot, 2001). A similar conclusion was reached by Keil and Hagen (2000) in an independent study on a Bavarian squall-line (close to the MAP area). The use of the MC2 model at a somewhat lower resolution $(3 \mathrm{~km}$ ) during MAP SOP bears some risk of underestimating convective precipitation. However, the choice of the resolution was dictated mainly by the computer resources.

A very simple land surface scheme (Benoit et al., 1989), based on the Force-restore method, is used during the MAP. The surface temperature is obtained with an energy balance equation. Parameterisation of the snow-melt process is not available in this scheme. Since the MC2 was run for 30 hours only and the snow cover was updated for each forecast from the driving Swiss Model (SM), the feedback of snowmelt to the atmospheric circulation, although important in this area for medium- and long-range forecasts, may be considered small compared with other dynamic and physical factors. However, snow melting is considered in the hydrological model since it is important in a continuous forecast of stream flow.

The hydrological model used for this study is the distributed flood-forecasting model WATFLOOD, based on a concept of the Grouped Response Unit (GRU) (Kouwen et al., 1993), in which all hydrologically similar areas within an area receiving equal meteorological stimuli are treated as one modelling unit even if the areas are not contiguous. For instance, all forested areas within a grid defined by the meteorological forcing data are treated as one forest and its runoff contribution is added to the runoff from other areas such as bare soil, cropped areas, wetlands, glaciers, etc. This provides an efficient, scale-independent procedure to forecast flows for any catchment having a response time ranging from one hour to several weeks, using all available data. This includes data produced by a high-resolution numerical weather prediction model or weather radar data. Remotely-sensed land cover data and digital elevation models are used to account properly for the effect of vegetation and topography on storm runoff. Each event can be up to one year in length.

The hydrological processes incorporated in WATFLOOD include: interception, infiltration, evapotranspiration, interflow, baseflow, overland routing and channel routing. The routing of water through the channel system is accomplished using a storage routing technique which involves a straightforward application of the continuity equation. The flow is related to the storage through Manning's formula. Continuous simulation of hydrological response can be carried out by chaining a number of events. For this study, daily events were made up of the 24 hour MC2 forecast and 24 hour recorded streamflows. For the real-time flow forecasting application, an event is added to the sequence when a new forecast is produced. Thus the MAP SOP provided data for 73 events covering the period from September 4 to November 15, 1999.

Another unique aspect of this study is that the WATFLOOD model was not recalibrated. The original calibration for the Columbia River in the Rocky Mountains in Canada (Kouwen et al., 2003) was applied to the European Alpine region with only one change; in general, rivers in Europe are no longer in their natural state and resistance parameters require a downward adjustment of approximately $50 \%$.

The linking of hydrological and atmospheric models is often based on a one-way coupling approach. The hydrological models are linked to atmospheric models through a simple forcing method by using only the atmospheric model output. Kim et al. (1998) presented a well-designed numerical modelling system, which coupled atmospheric, land surface and hydrological models to integrate regional climate prediction and assessments of atmospheric, land surface and hydrological processes over a mountainous area in California. During the MAP Special Observation Period (SOP), WATFLOOD uses the one-hour precipitation accumulation and temperature from $\mathrm{MC} 2$ at each hour of simulation. Both models use their own simplified land surface physical process (Benoit et al.2002). WATFLOOD uses a water balance calculation as opposed to a water and energy balance calculation in MC2. Oneway linking can be misleading since the land-surface is treated independently in each model, resulting in 
inconsistent basin state variables. This can be avoided if the two models share the same land-surface scheme. The experience gained in such one-way off-line coupling of atmospheric and hydrological models will be useful in developing numerical weather prediction models of the full hydrological cycle with full coupling of atmospheric, oceanic and hydrological models.

\section{Model settings}

During the MAP SOP, MC2-3km was run as the last stage in a chain of models, where each consecutive model uses data from the previous model (Benoit et al, 2002). The initial and lateral boundary conditions of $\mathrm{MC} 2-3 \mathrm{~km}$ were provided by a MC2-14km run which, in turn, was driven by the Swiss Model (SM) at a similar resolution. The need for an MC2 model run at the same resolution as the SM is due to a requirement that the refinement in horizontal resolution from the SM to MC2 cannot be more than a factor of 3 due to differences affecting the numerical schemes and physical parameterisations. This refinement factor can go up to 10 when MC2 is used for both coarse and high resolution simulations. Thus MC2 had to be run twice in any case and making the refinement with the same model was preferred. The MC2-3km covered the alpine region of Europe $\left(42^{\circ}\right.$ $\mathrm{N}-49^{\circ} \mathrm{N}$ in latitude and $4^{\circ} \mathrm{E}-15^{\circ} \mathrm{E}$ in longitude), including eastern France, northern Italy, southern Germany, most of Austria, and the whole of Switzerland (Fig. 1). The major catchments included are the headwaters of the Danube, Rhine, Po and Rhone rivers.

WATFLOOD was run over a latitude/longitude grid covering an area of $46^{\circ} \mathrm{N}-51^{\circ} \mathrm{N}$ by $6^{\circ} \mathrm{E}-16^{\circ} \mathrm{E}$ (Fig. 2). The horizontal resolution was 2.0 minutes in the north-south direction and 3.0 minutes in the east-west direction, which is approximately $3.7 \mathrm{~km}$ in each direction. Data from a total of 33 stream gauging stations were available and used for evaluation during the MAP SOP. These multinational stations include 13 in Switzerland, 3 in Austria, 1 in Italy, and 16 in Germany (Fig. 2). The relevant information for the stations used in this study is listed in Table 1. A considerable amount of information relating to the catchment is required by WATFLOOD to produce accurate results. These data include elevation, land use, drainage direction, temperature and precipitation for the time being studied.

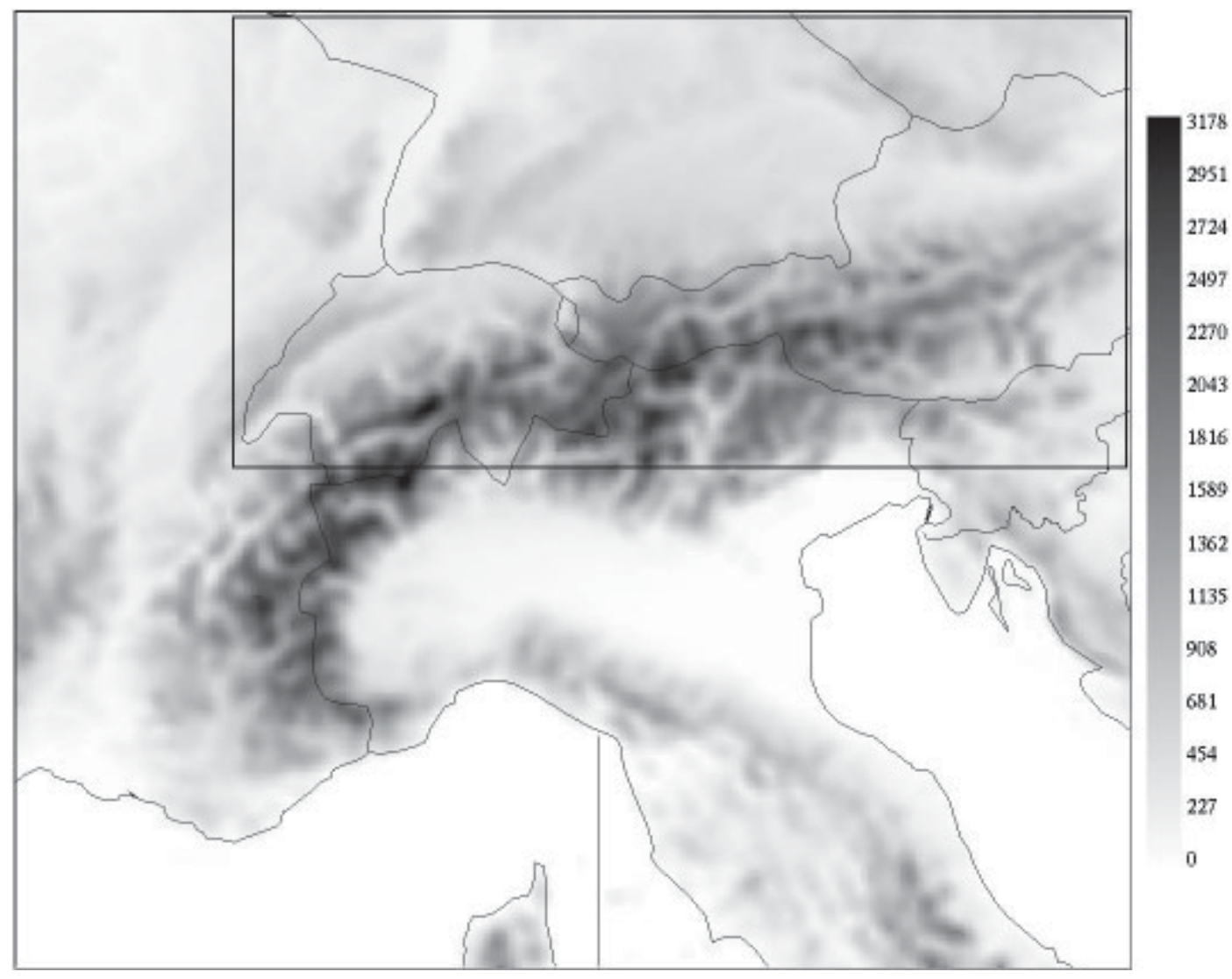

Fig. 1. The computational domain of the MC2-3km. Terrain elevation is plotted in grey shading (in metres) with highest terrain in dark. The political boundaries and longitude segments are drawn in black lines. 


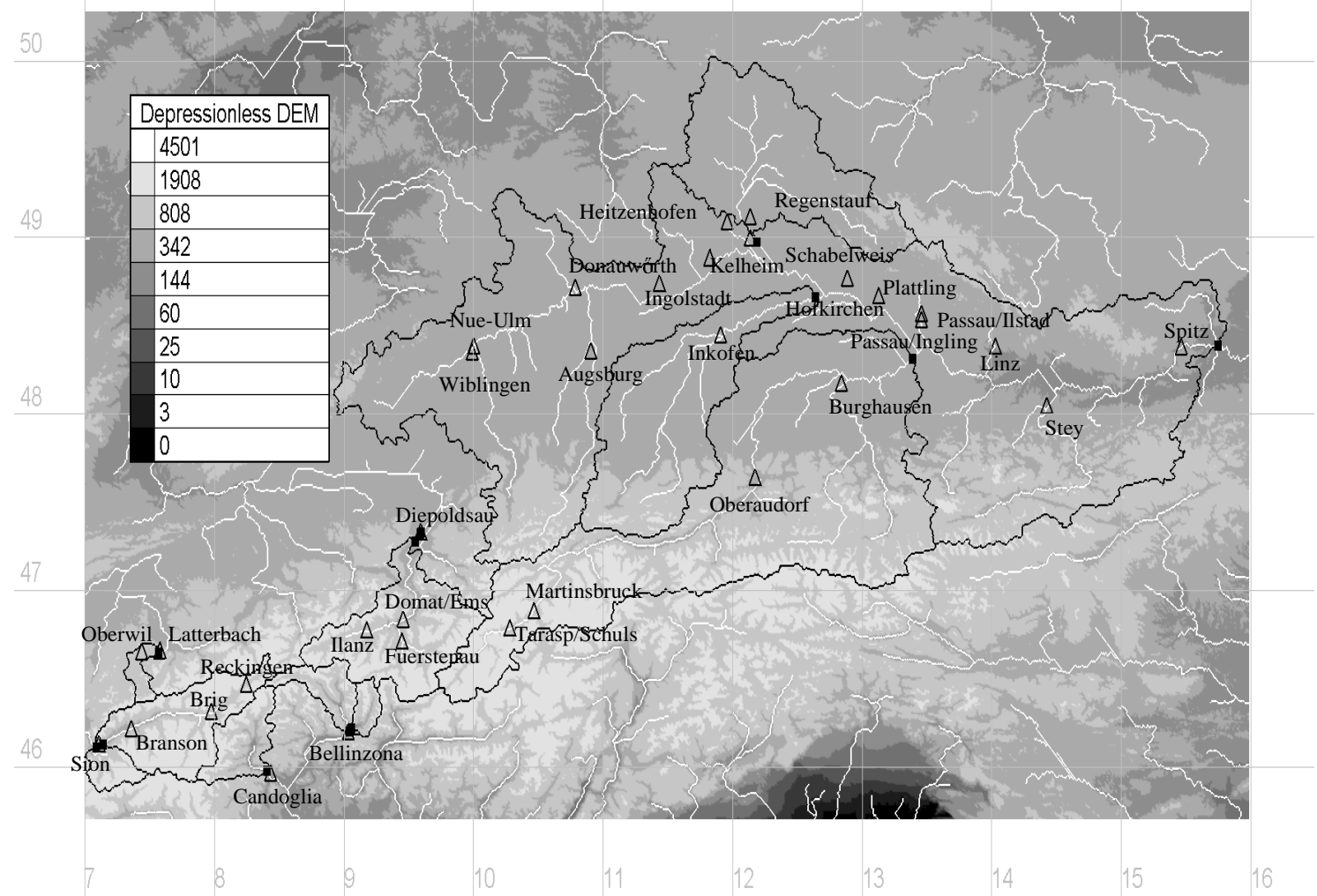

Fig. 2. WATFLOOD model grid (latitude/longitude) covering an area of $46^{\circ} \mathrm{N}-51^{\circ} \mathrm{N}$ by $6^{\circ} \mathrm{E}-16^{\circ}$ E. Terrain elevation is plotted in grey shading (in metres) with highest terrain in light. Major rivers are drawn in white lines, and the catchment boundaries in black lines. The names of the 33 streamflow stations, together with their location (in open triangles) are printed on the map. Black dots indicate the catchment outlets.

Table 1. Station information for model domain

\begin{tabular}{lllllll}
\hline $\begin{array}{l}\text { Streamflow } \\
\text { Station }\end{array}$ & Description & $\begin{array}{l}\text { Latitude } \\
\left({ }^{\circ} \mathrm{N}\right)\end{array}$ & $\begin{array}{l}\text { Longitude } \\
\left({ }^{\circ} \mathrm{E}\right)\end{array}$ & $\begin{array}{l}\text { Drainage } \\
\text { Area }\left(\mathrm{km}^{2}\right)\end{array}$ & $\begin{array}{l}\text { Model Drainage } \\
\text { Area }\left(\mathrm{km}^{2}\right)\end{array}$ & $\begin{array}{l}\text { Difference } \\
(\%)\end{array}$ \\
\hline Ilanz & Vorderrhein & 46.7771 & 9.1741 & 776 & 752 & -3.1 \\
Tarasp/Schuls & Inn & 46.7891 & 10.2786 & 1584 & 1574 & -0.6 \\
Linz & Danube & 48.3853 & 14.0275 & 78190 & 76894 & -1.7 \\
Spitz & Danube & 48.3833 & 15.4622 & 95970 & 94322 & -1.7 \\
Neu-Ulm & Donau & 48.3887 & 10.0014 & 7578 & 7553 & -0.3 \\
Kelheim & Donau & 48.8861 & 11.8232 & 22950 & 23040 & 0.4 \\
Hofkirchen & Donau & 48.6723 & 13.1262 & 47496 & 47150 & -0.7 \\
Brig & Rhone & 46.3174 & 7.9750 & 913 & 901 & -0.8 \\
Bellinzona & Ticino & 46.2000 & 9.0330 & 1515 & 1526 & -0.8 \\
Candoglia & Toce & 45.9667 & 8.4330 & 1532 & 1525 & -0.8 \\
\hline
\end{tabular}

The characteristics of the drainage layer database came from the gridded Digital Elevation Model (DEM), called the Defense Land Mass System (DLMS) (Volkert, 1990). They consist of an ordered array of gridded elevations at regularly spaced intervals with 3" resolution (i.e. 1200 data points per degree). The geometric resolution is about $93 \mathrm{~m}$. Each file consists of elevation data units expressed in metres relative to mean sea level. The elevation data were used for the storage routing scheme (Fig. 2). For the study area, the drainage layer databases were created automatically using the program MapMaker. This program uses output from the image processor EASI/PACE produced by PCI Industries. EASI/PACE (PCI Geomatics, 1998) uses the DEM to calculate such fields as flow direction and flow 
accumulation, and delineates catchments. From these fields, MapMaker then calculates the flow characteristics of the drainage layer database. Then the program processes the land cover information so that it can be used by WATFLOOD. During each step of the drainage layer database setup, the data were scrutinised to avoid possible errors. Meanwhile, the programs perform their own validation procedures to make sure that the flow networks are logical, i.e. ensuring water flows to a lower elevation and avoiding dead ends in the flow networks (Kouwen et al., 2000).

The land-cover data were derived from the Distributed Active Archive Center from USGS Eros Data Center, the Global Land Cover Characteristics Data Base. They were generated at a resolution of 1-km for use in a wide range of environmental research and modelling applications, and were developed on a continent-by-continent basis. All continental databases share the same map projections (Interrupted Goode Homolosine and Lambert Azimuthal Equal Area), have 1-km nominal spatial resolution and are based on 1-km Advanced Very High Resolution Radiometer (AVHRR) data. A core set of thematic maps derived by aggregation of seasonal land cover regions is included in each continental database to provide flexibility for a variety of applications. In the data set, seven different cover types across the Alps area were: Coniferous Forest, Deciduous Forest, Water, Agriculture, Barren land, Urban and Glacial.

Distributed precipitation and temperature data were generated by the MC2 numerical weather prediction model. The data were processed once a day to produce 24-hour forecasts of precipitation and temperature. Data were transformed into the WATFLOOD latitude-longitude grid with hourly time steps for processing of the MAP SOP.

\section{Results and discussion}

The performance of MC2 with respect to forecasting precipitation can be evaluated by comparing computed with observed hydrographs in terms of the four situations:

1. The forecast flows match the observed flow data

2. The $\mathrm{MC} 2$ derived flows appear in the wrong location and/or the wrong time

3. MC2 produces a significant flow at one or more locations where there is no such event

4. MC2 computes no significant flow while observations show increased flows

The results of the comparison between the observed streamflow and the forecasted streamflow are presented using the MC2-WATFLOOD linked models on a station-

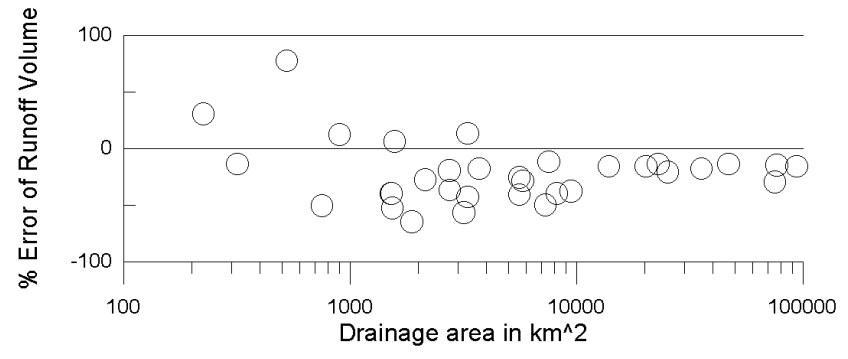

Fig. 3. Error in the predicted runoff (in percent) as a function of drainage area $\left(\right.$ in $\mathrm{km}^{2}$ ) for all the 33 stations during the MAP SOP.

by-station basis. The predicted magnitude of the storm is also of interest, but was not the focus of this study. More emphasis is placed on the ability of the MC2/WATFLOOD linkage to identify areas where a potential for flooding exists. For a large catchment, real-time flow forecasting can be updated using radar and/or flow observations. Modelling such a catchment provides a first alert and an awareness of what may occur. Table 1 lists 10 of the 33 streamflow stations used in this study (their locations, actual and modelled drainage area as well as the percent difference between the actual and modelled drainage area). The 10 selected stations are representative of the 33 and are also the ones that appear to be least affected by regulation. Figure 2 shows the model domain and streamflow gauge locations.

In general, the MC2/WATFLOOD model underestimated the total runoff during MAP SOP and the underestimation was larger at higher elevations. This is consistent with the study of Benoit et al. (2002): the precipitation was underpredicted by MC2 by a factor of two during MAP SOP. After the field experiment, a coding error in the cloud microphysics scheme of MC2 was found, which explains this underestimation to a large extent. Further studies are needed to quantify this statement accurately. Figure 3 shows the percentage error for all 33 stations used in the study. The error for larger drainage areas is reduced because much of the flow is base flow which is initialised at the start of the simulation and is not subject to much random error. While the point with the $77 \%$ error is for a highly regulated site, Fig. 3 shows an underestimation for most of the intermediate basins.

Figures 4 and 5 show the observed and computed hydrographs for the stations listed in Table 1. Figure 4 shows the results for the headwaters of four major rivers: the Rhone, Rhine, Danube and Po. The Ticino and the Toce contribute to the Po river and the Inn contributes to the Danube. All stations on Fig. 4 have drainage areas less than $1600 \mathrm{~km}^{2}$. Figure 5 shows the results for stations along the Danube River which range in drainage area from $7578 \mathrm{~km}^{2}$ at NeuUlm to $94322 \mathrm{~km}^{2}$ at Spitz. 

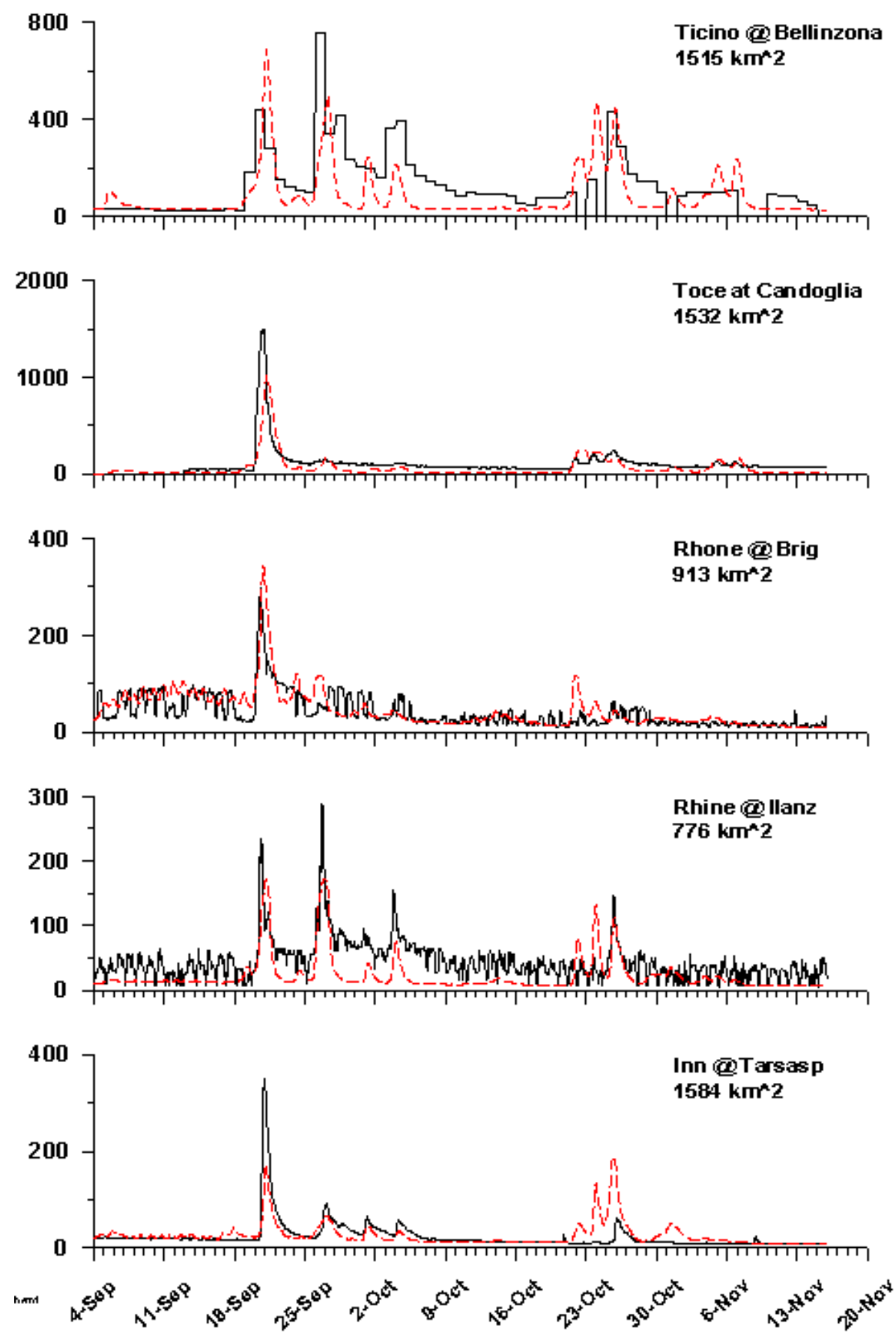

Fig. 4. Streamflow (in $\mathrm{m}^{3} \mathrm{~s}^{-1}$ ) for the period of Sep. 4 to Nov. 17, 1999, for the 4 major rivers. The observed streamflow is plotted in black lines, and the simulated one in red lines.

Unfortunately, reservoir data were not available for this study. Many gauge sites used in the study show clear signs of regulation. For instance, the Rhone at Brig and Ilanz (Fig. 4) and the Danube at Donauworth and near Spitz (Fig. 5). However, it is also apparent from the figures, that the regulation affects mostly the temporal distribution of flow over a 24 hour period. Compared to the total flow and drainage areas, the reservoir storage is small. This results in the computed hydrograph being smoother than the observed hydrograph. As a result, regulation (probably) does not affect the outcome or interpretation of the results. Figure 4 shows that large events quite overwhelm the effects of regulation and indicate that the regulatory effects on the results are not of major concern. 

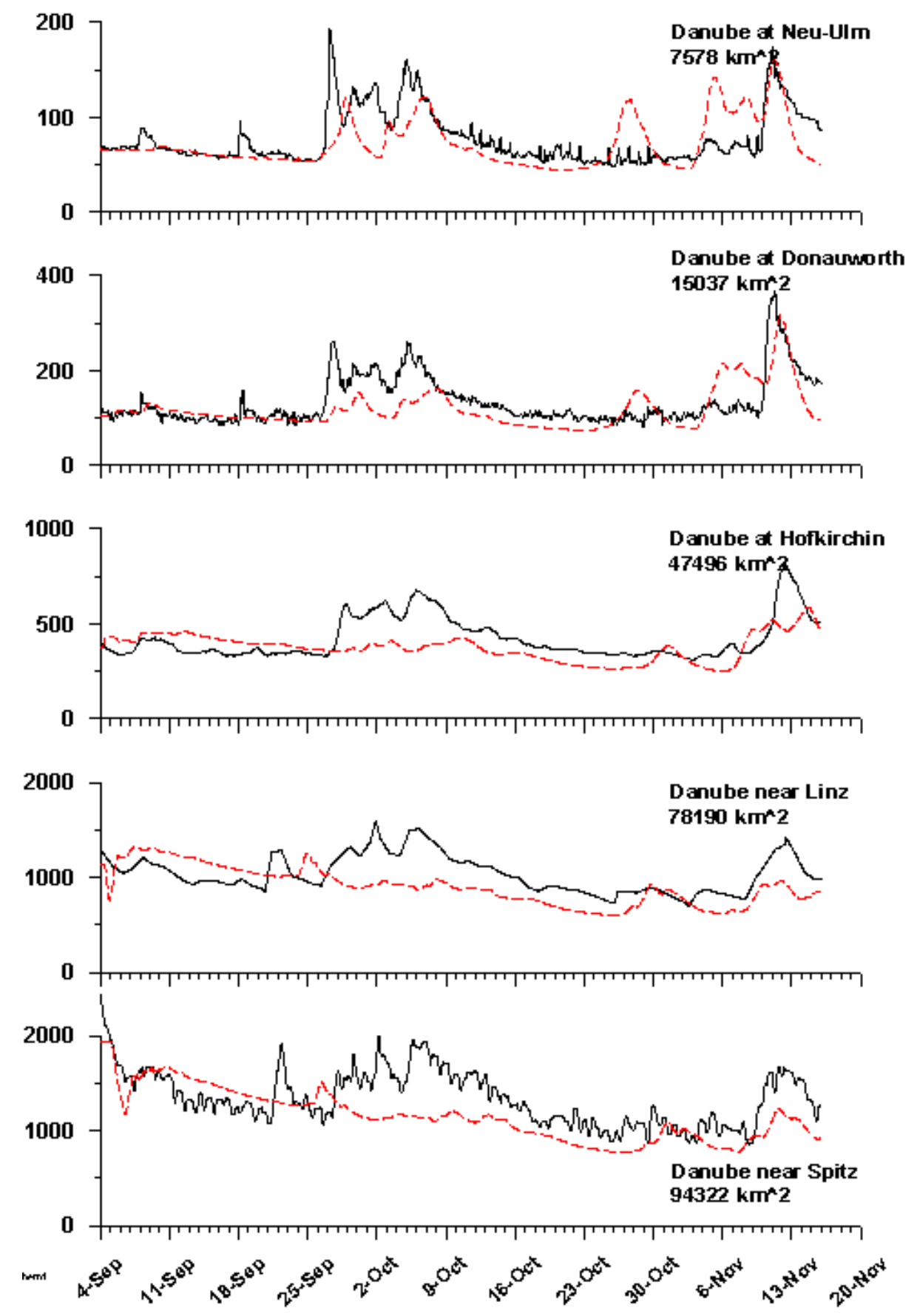

Fig. 5. Streamflow (in $\mathrm{m}^{3} \mathrm{~s}^{-1}$ ) for the period of Sep. 4 to Nov. 17, 1999, for stations along the Danube river. The observed streamflow is plotted in solid black lines, and the simulated one in broken red lines.

When describing the results of hydrological modelling, various statistical indicators such as the RMS error of the hourly flows or the Nash-Sutcliffe (1970) efficiency indicator are often used to describe how well the computed hydrographs compare with the observed hydrographs. However, if a hydrograph is predicted very well but is just a few hours early or late, the statistical indicators can suggest that it was a very poor fit but the forecaster may find that the flow was very well predicted. For the 10 week study period, the Nash-Sutcliffe Indicator values were all negative yet the computed hydrographs generally followed the major trends of the observed hydrographs. In this paper, a qualitative measure of success seems appropriate and the relative success of the flow forecasts are based on the writers' 
experience in computing hydrographs using a variety of precipitation data, including rain gauges, weather radar and numerical weather models. The results are described in the context of using predicted numerical weather data, which until now could not be said to be more reliable than actual observations.

For this type of analysis, a successful flow prediction might mean a computed hydrograph with a peak flow within approximately $50 \%$ of the recorded hydrograph peak and a time of peak displaced by no more than the time of concentration of the catchment. Others might suggest another definition - it would all depend on the eventual use of the forecast. The readers can draw their own conclusions based on their personal experience in computing flow forecasts in their own setting.

Overall, the prominent features of the storm hydrographs for four events between September 21 and October 5 are reproduced in the headwaters of the Rhone, Ticino, Rhine, Inn and Danube rivers. This area straddles the SwissAustrian border. The flows computed for the Danube at NeuUlm and Donauworth showed at least some response to rainfall but the catchments to the east, namely the Lech,
Amper and Inn Rivers (not shown) do not show any substantial hydrographs for this period. This deficiency is evident on the flow plots for the Danube below these rivers at Hofkirchen, Linz and Spitz (Fig. 5). In comparing the MC2 forecast with the Alpine Composite Radar on the MAP website (http://www.map2.ethz.ch/sop-doc/catalog/ products/) for September 28, radar shows a substantial amount of rain fell on the Austrian Alps but MC2 did not forecast this rain. On September 30, radar shows widespread rain over Bavaria and the Austrian Alps but again MC2 forecast rain only in a small area in the headwaters of the Danube. This is reflected in the computed hydrographs for the Danube at Neu-Ulm and Donauworth. On October 3 and 4, another event with widespread rainfall is recorded by the MAP Alpine Composite Radar. MC2 forecast rain for the same area but with much lower intensities than indicated by the radar. This deficiency in the MC2 forecast rain is evident in the under-predicted flows in the Danube at Hofkirchen, Linz and Spitz.

Three measurable events (not flood events) occurred from October 22-24 on the Ticino and Rhine above Chur. Hydrographs were computed at all stations in the domain.

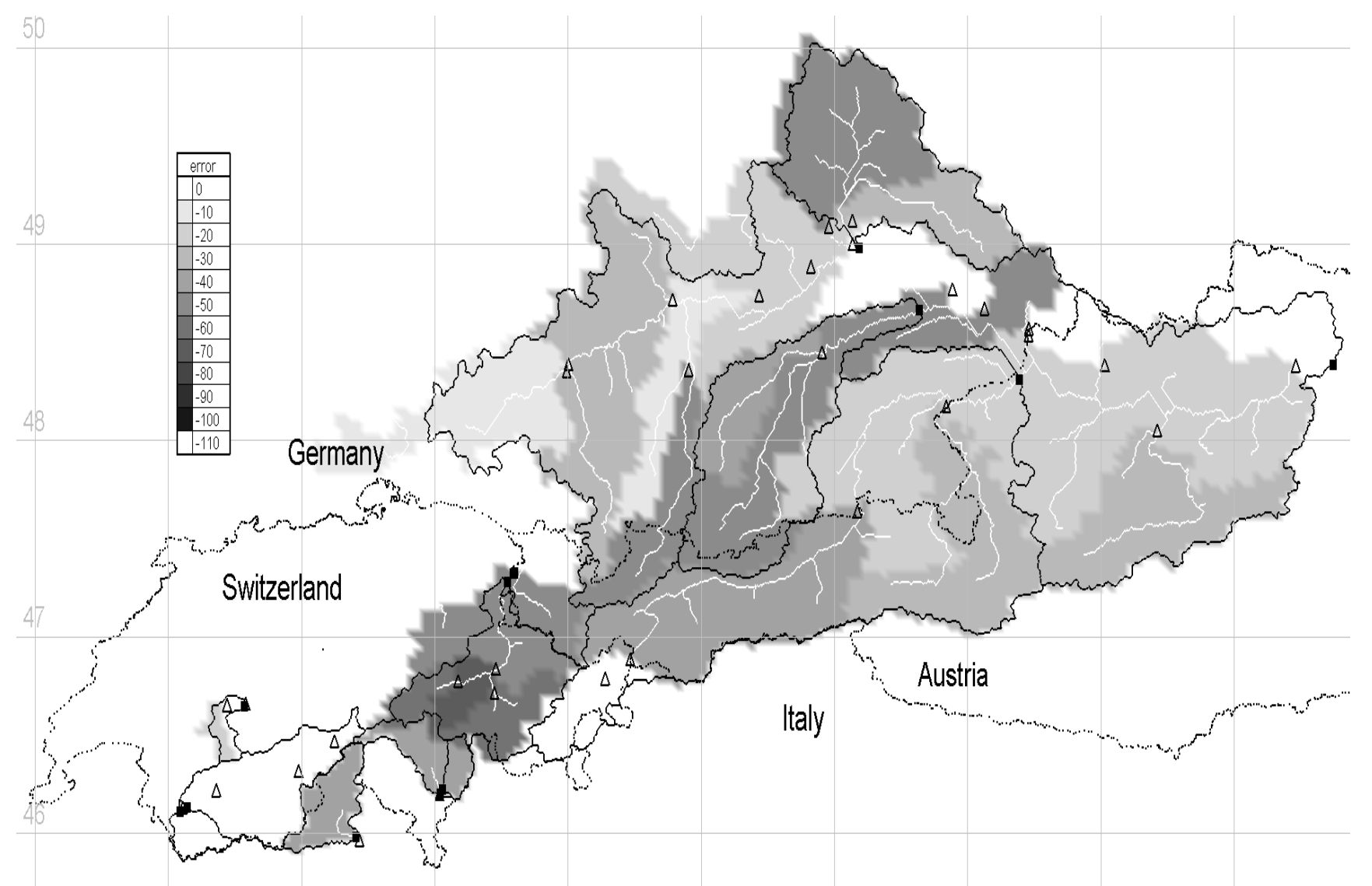

Fig. 6. Map of the study area showing areas with under-estimation of runoff. Solid lines are catchment outlines, triangles are flow stations and broken lines are country borders. 


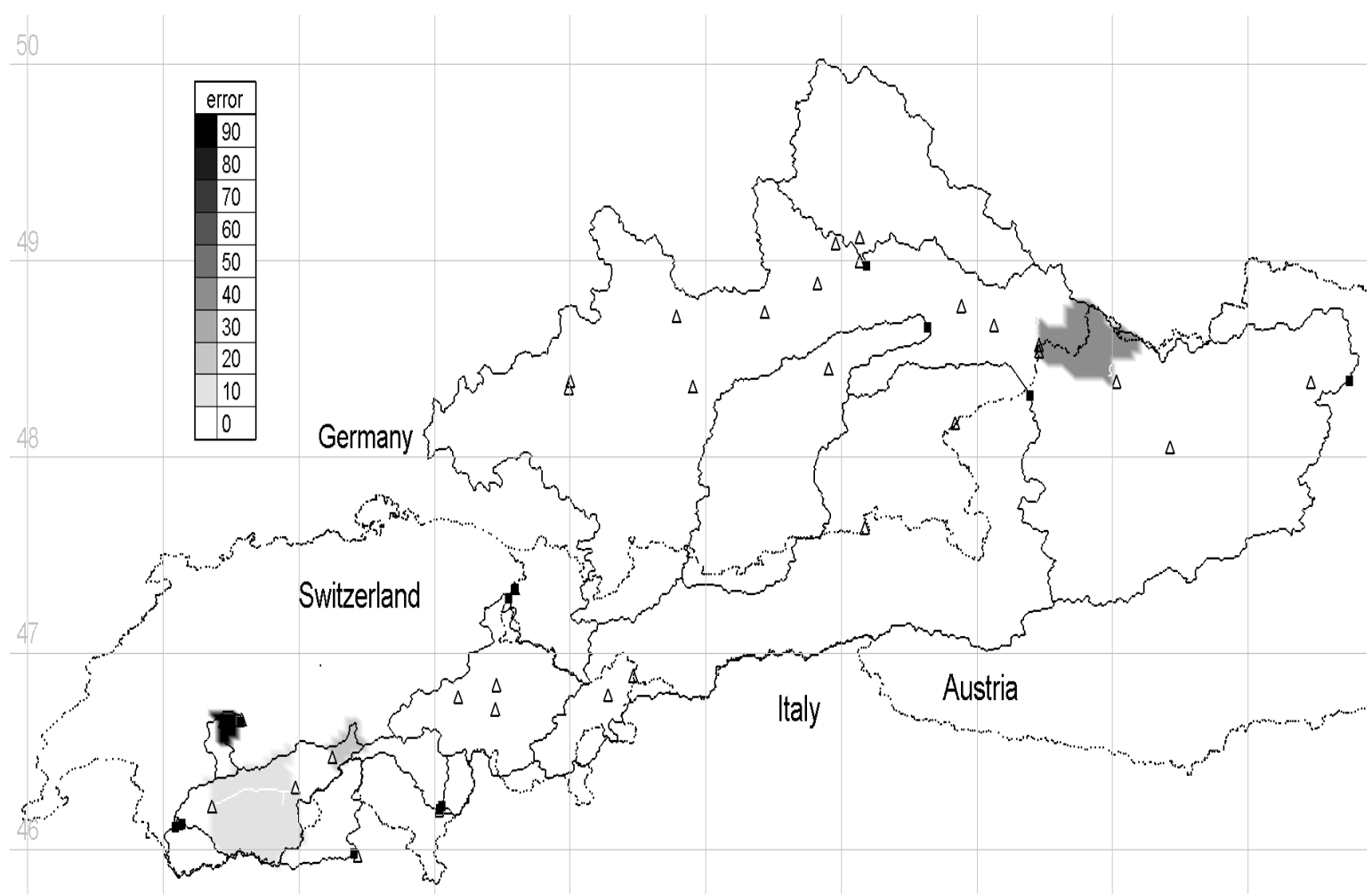

Fig. 7. Map of the study area showing areas with over-estimation of runoff. Solid lines are catchmentoutlines, triangles are flow stations and broken lines are country borders.

At Brig, Ilanz, Bellinzona and Candoglia, small hydrographs were modelled reasonabaly. From October 23-24, MC2 predicted rain for the Danube above Neu-Ulm, the Iler above Wiblingen (not shown) and the Inn at Tarsasp. For this same period, radar showed some widespread spotty rain on October 23 and a band of rain that remained to the west of the modelled catchments. This MC2 prediction resulted in hydrographs overestimated for the upper reaches of the Inn and Danube which converged with observations when routed downstream to produce the hydrographs beginning on October 30 for the Danube at Linz and Spitz

On November 2-3, 1999, MC2 forecast an event centred in the Liechtenstein area. Hydrographs were predicted incorrectly for the Rhine above Oberwil (not shown) and the Danube at Neu-Ulm. As with the earlier events, the hydrograph was routed downstream and showed up approximately one week later at Linz and Spitz, where it blended in with another event that was predicted by MC2 but under-estimated. This last event during the MAP SOP was centred in the upper reaches of the Danube and was modelled very well at Neu-Ulm. This hydrograph was routed down the Danube past the various flow stations and approximately matches the increase in the flows at Linz and Spitz. Overall, the simulated flows of the Danube at Spitz matched the observed flow very well except for the period from September 28 to October 9.
The deficit in the Danube flows can be traced back to the events in central Austria missed during this period. Figures 6 and 7 illustrate the locations where MC2 under- and overestimated precipitation. There is some over-estimation in the upper reaches of the Inn river, the Rhone and parts along the main stem of the Danube but Fig. 6 shows an extensive region with a water deficit. The observed hydrograph at Spitz shows $90 \mathrm{~mm}$ runoff from the whole catchment for the MAP SOP while the computed hydrograph represents only $75 \mathrm{~mm}$. More than $50 \%$ of this is base flow.

In a more detailed analysis, Liu (2001) summarises the overall performance of MC2 using all 33 flow stations. Within the MAP-SOP, 11 events were simulated and generated 97 hydrographs at various locations. Of the recorded hydrographs, 84 were predicted by MC2 and 13 were missed by MC2. In addition, 21 hydrographs were predicted by MC2 that did not occur. As a result, using MC2 for flood alert and early warning, there is an $87 \%$ chance that it can predict an increase in flow correctly while there is a $13 \%$ chance that it will miss the event. There is also a $22 \%$ possibility it will produce a false alarm. Overall, this confirms that MC2 is able to predict storms for large domains although there is uncertainty in terms of the prediction for individual rivers. These figures are based on using MC2 forecast data only and flows were not adjusted with recorded data of any kind. Flow forecasts on larger basins obviously 

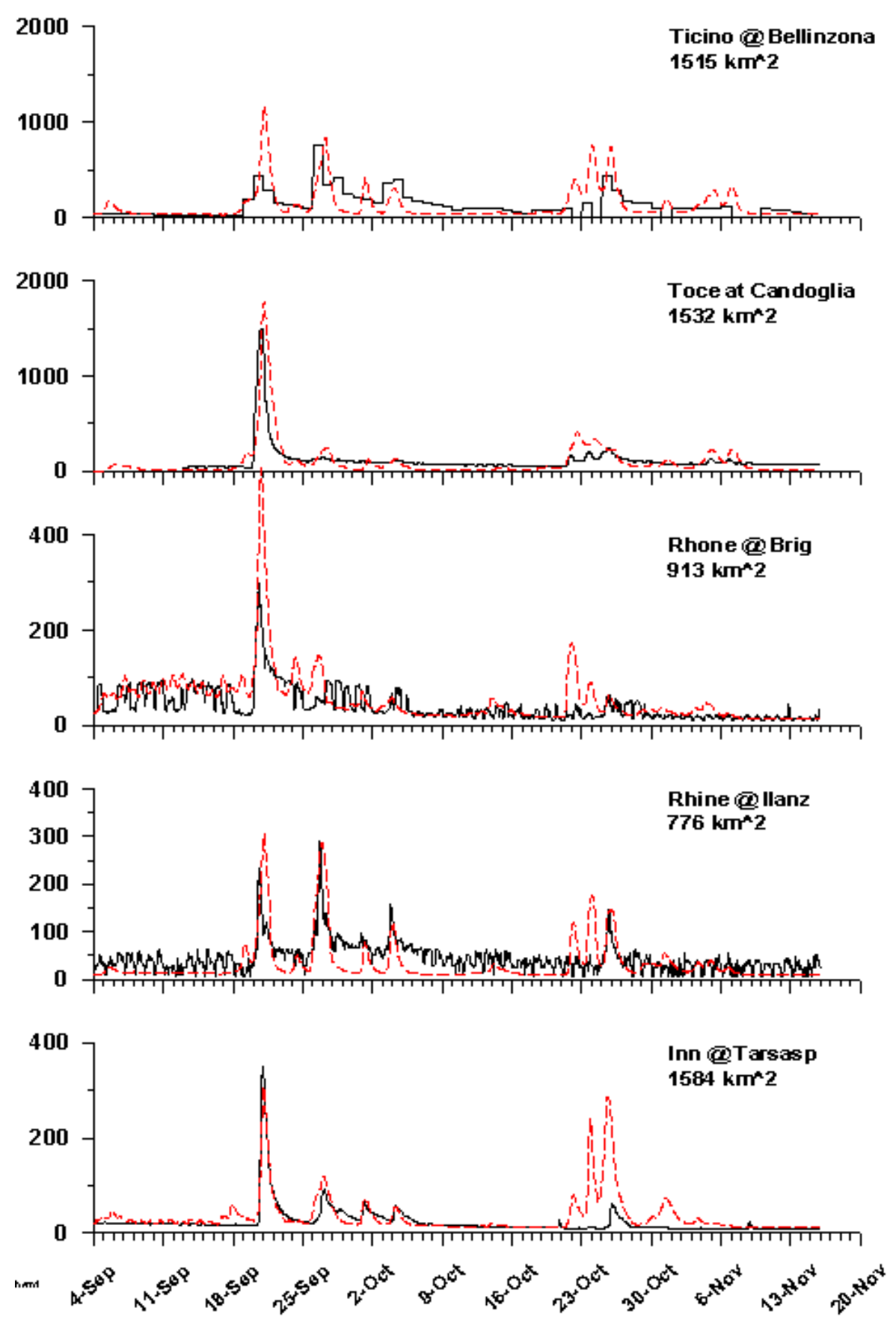

Fig. 8. Streamflow (in $\mathrm{m}^{3} \mathrm{~s}^{-1}$ ) based on increasing the MC2 derived precipitation by 50\% for the period of Sep. 4 to Nov. 15, 1999, for stations along the Danube river. The observed streamflow is plotted in solid black lines, and the simulated one in broken red lines.

would be improved if recorded flows, radar and/or gauged precipitation were used up to the time of the forecast. The use of a numerical weather model can usefully extend the flow forecast by the length of the weather forecast, which in this case involves MC2 with a 24-hour forecast.

\section{Sensitivity study}

As discussed earlier, a coding error was found after the field experiment: the time step used for the calculation of sedimentation in solid phase (ice crystals and graupel) was twice as large as it should be. This reduced the precipitation rate by a factor of two for the cold clouds (temperature of which is below zero degree Celsius). Since the sedimentation 

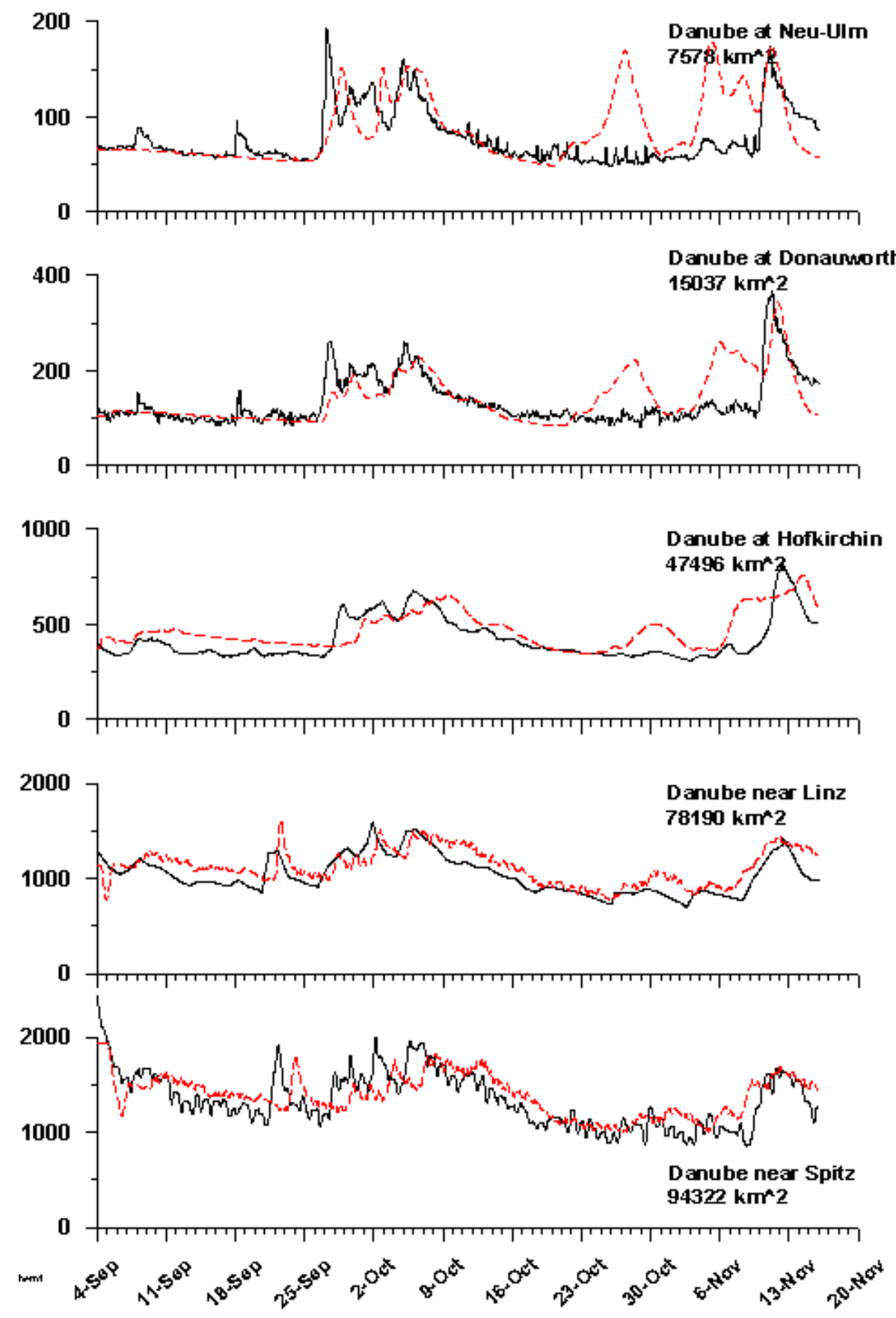

Fig. 9. Streamflow (in $\mathrm{m}^{3} \mathrm{~s}^{-1}$ ) based on increasing the MC2 derived precipitation by 50\% for the period of Sep. 4 to Nov. 15, 1999, for stations along the Danube river. The observed streamflow is plotted in solid black lines, and the simulated one in broken red lines.

in solid phase is involved in most of the precipitation events over the alpine region, in particular for high altitude regions and during late autumn, the overall under-prediction of precipitation in MC2 is close to a factor of two. To evaluate the impact of this under-prediction of precipitation on the simulated hydrographs, a sensitivity study using WATFLOOD was re-run over the entire period with the MC2's precipitation increased by $50 \%$, keeping in mind that re-run MC2 at a resolution of $3 \mathrm{~km}$ is computationally expensive and therefore not easily feasible.

Figures 8 and 9 show the flows for the same locations as those shown in Figs. 5 and 6 but with the increased precipitation. What is evident now is that none of the hydrographs is under-predicted and the flow for the Danube at Spitz is over-predicted by just three percent at $92 \mathrm{~mm}$. Of course the events from October 21 to October 25 that 
were over-predicted before are now even more overpredicted. However, these events contributed relatively small flows for the lower stations along the Danube at Linz and Spitz. Thus, for the larger domain, MC2 predicted the flow pattern very well once the coding error was taken into account and MC2's precipitation was increased by $50 \%$. These results (Figs. 8 and 9) show that MC2 should be fairly capable of forecasting major events for large domains because during the MAP SOP, MC2 did not miss any substantial precipitation events.

\section{Conclusions}

The effectiveness of a Numerical Weather Prediction Model for flood alerts on a regional basis has been examined. The MC2 atmospheric model used in this study is a 3-D fully compressible model, which uses a semi-implicit semiLagrangian time scheme to solve the Euler equation. The last stage of MC2 in a model chain was run at a resolution of $3 \mathrm{~km}$ covering the alpine region of Europe, which included the study area of this project, namely the headwaters of the Po, Rhine, Rhone and Danube rivers.

The hydrological model WATFLOOD was coupled to MC2. It is a distributed flood-forecasting model that can incorporate remotely sensed data and digital elevation data into hydrological modelling. The storage routing technique involving the continuity equation and the Manning Formula is applied in WATFLOOD to model the physical process.

The one-way coupling technique linking atmospheric and hydrological models was applied to the Alpine study areas. Precipitation and temperature data produced by MC2 were incorporated into the WATFLOOD model to simulate runoff and the results were compared with the observed flows. Where the MC2/WATFLOOD flow predictions did not match the observations, the MC2 precipitation forecast and Alpine Composite Radar data were used to explain the deficiencies in the hydrographs. For each unsuccessful flow forecast, it was possible to determine, qualitatively, that the MC2 precipitation forecast was in error. However, once the coding error in the MC2 microphysics scheme was taken into account, all recorded hydrographs were predicted to show that a flow forecast from linked weather and hydrological models can serve as a useful first alert and quantitative forecast. Only one event of flood magnitude occurred in one location during the MAP SOP, namely the September 20-23 event on the Toce River above Candoglia. for this event, the hydrograph peak was over-predicted by $<20 \%$ and $<6$ hours late (Fig. 8).

The simulated runoffs match the regionally observed flow quite well. This information could be valuable in predicting and forecasting the occurrence of high flows at specific times and locations for Alpine regions. The methodology seems especially appropriate to produce an initial alert, to be followed up by more detailed modelling for specific problem areas using radar and other real-time observations.

\section{Acknowledgments}

The hydrographs were prepared by Maggie X. Liu and her efforts are deeply appreciated and acknowledged by the authors. The German flow data were kindly provided by Dr Alfons Vogelbacher from the Bavarian Water Survey, the Candoglia gauge data by CNR-Istituto Idrobiologico di Pallanza through Regione Piemonte, the Austrian data by the Austrian Hydrographic Service and the Swiss data by Bundesamt Für Wasser und Geologie. This study was financed by Environment Canada, the National Science and Engineering and Science Research Council of Canada and the University of Waterloo. The contributions of all these organisations and individuals are very much appreciated.

\section{References}

Bélair, S. and Mailhot, J., 2001. Impact of horizontal resolution on the numerical simulation of a midlatitude squall line: implicit versus explicit condensation. Mon. Weather Rev., 129, 23622376.

Benoit, R., Côté, J. and Mailhot, J., 1989. Inclusion of a TKE boundary layer parameterization in the Canadian regional finiteelement model. Month. Weather Rev., 117, 1726-1750.

Benoit, R., Desgagné, M., Pellerin, P., Perllerin, S., Chartier, Y. and Desjardins, S., 1997. The Canadian MC2: A semiLagrangian, semi-implicit wideband atmospheric model suited for finescale process studied and simulations. Mon. Weather Rev., 125, 2382-2415.

Benoit, R., Pellerin, P., Kouwen, N., Ritchie, H., Donaldson, N., Joe, P. and Soulis, E.D., 2000. Toward the use of coupled atmospheric and hydrologic models at regional scale. Mon. Weather Rev., 128, 1681-1706.

Benoit, R., Schär, C., Binder, P., Chamberland, S., Davies, H.C., Desgagné, M.. Girard, C., Keil, C., Kouwen, N., Lüthi, D., Maric, D., Müller, E., Pellerin, P., Schmidli, J., Schubiger, F., Schwierz, C., Sprenger, M., Walser, A., Willemse, S., Yu, W. and Zala, E., 2002. The real-time ultrafinescale forecast support during the Special Observing Period of the MAP. Bull. Amer. Meteor. Soc., 83, 85-109.

Bougeault, P., Binder, P., Buzzi, A., Dirks, R., Houze, R., Kuettner, J., Smith, R.B., Steinacker, R. and Volkert, H., 2001. The MAP Special Observing Period. Bull. Amer. Meteor. Soc., 82, 433462.

Keil, C. and Hagen, M., 2000: Evaluation of high resolution NWP simulations with radar data. Phys. Chem. Earth (B), 25, 12671272.

Kim, J., Miller, N.L., Guetter, A.K. and Georgakakos, K.P., 1998. River flow response to precipitation and snow budget in California during the 1994/95 winter. J. Climate, 11, 2376-2386.

Kong, F. and Yau, M.K., 1997. An explicit approach to microphysics in MC2. Atmos.-Ocean, 35, 257-291. 
Kouwen, N., Soulis, E.D., Pietroniro, A., Donald, J. and Harrinton, R.A., 1993. Grouping Response Unit for distributed hydrologic modelling. ASCE J. Water Resour. Manage. Plann., 119, 289305.

Kouwen, N., Soulis, E.D. and Seglenieks, F.R., 2000. The creation of the drainage layer database of the WATFLOOD distributed hydrologic model over the Trent-Severn waterway. Department of Civil Engineering, University of Waterloo, Waterloo, ON., Canada.

Kouwen, N., Danard, M., Bingeman, A., Luo, W., Seglenieks, F.R. and Soulis, E.D., 2003. Case study: watershed modeling with distributed weather model data. ASCE J. Hydrol. Eng., in press.

Liu, M.L., 2001. Flood alert based on linked numerical weather and hydrological models. M.A.Sc. Project Report, Department of Civil Engineering, University of Waterloo, Waterloo, ON., Canada.
Misra, V., Yau, M.K. and Badrinath, N., 2000. Atmospheric water species budget in mesoscale simulations of lee cyclones over the Mackenzie River Basin. Tellus, 52A, 140-161.

Nash, J.E. and Sutcliffe, J.V., 1970. River flow forecasting using conceptual models 1. A discussion of principles. J. Hydrol., 10, 282-290.

PCI Geomatics, 1998. EASI/PACE Users Manual, Version 6.3. PCI Geomatics, Ontario, Canada.

Tanguay, M., Robert, A. and Laprise, R., 1990. A semi-implicit semi-Lagrangian fully compressible regional forecast model. Mon. Weather Rev., 118, 1970-1980.

Volkert, H., 1990. An Alpine orography resolving major valleys and massifs. Meteorol. Atmos. Phys., 43, 231-234. 